Review Article

\section{Mild to moderate iodine deficiency in pregnancy: A matter of debate}

\author{
Hossein Delshad ${ }^{1}$ and Fereidoun Azizi ${ }^{2 \star}$
}

\author{
'Director, Micronutrient Research Office, Research Institute for Endocrine Sciences, Shahid \\ Beheshti University of Medical Sciences, Tehran I.R. Iran \\ ${ }^{2}$ Director, Research Institute for Endocrine Sciences, Shahid Beheshti University of Medical \\ Sciences, Tehran I.R. Iran
}

\section{Abstract}

During the last few decades painstaking efforts have been made to eliminate iodine deficiency through the world. Nowadays in regions where dietary iodine intake is adequate or borderline, the main focus is increasing dietary iodine supply in the target population during pregnancy and the first years of life. Severe iodine deficiency during pregnancy increases the risk of irreversible brain damage, intellectual disability, neurologic abnormalities, stunted growth, increased pregnancy loss, infant mortality, impairments in child development and cretinism. The potential effects of mild-to-moderate iodine deficiency are debated. Results from animal studies and observational human studies indicate that maternal mild-to-moderate iodine deficiency disturbs thyroid function in pregnancy and it also may affects fetal neurodevelopment. The effect of supplementation of iodine on thyroid function of pregnant women and their newborn, neurodevelopment of infants and cognitive performance of children have been investigated using iodine nutrition in pregnancy, based on median urinary iodine concentration. However they have found conflicting results regarding the benefits or harms of iodine supplementation in pregnancy. Although many epidemiological, interventional and clinical studies have supported the association between thyroid function in pregnant women and later psychomotor and mental development of their children, the effect of iodine supplementation in pregnant women on neurodevelopment of children is inconclusive. Even in areas with well-established universal salt iodization program, pregnancy could be at risk of having iodine deficiency and despite WHO/ICCIDD/UNICEF recommendation which believe that dietary iodine fortification during pregnancy depends primarily on the extent of pre-existing iodine deprivation, systematic dietary fortification needs to be implemented in this vulnerable group. However, iodine supplementation of mildly iodine deficient pregnant women may not have beneficial effects in their thyroid function or neurodevelopment of their children.

\section{More Information}

*Address for Correspondence: Fereidoun Azizi, Professor, Endocrine Research Center, Research Institute for Endocrine Sciences, Shahid Beheshti University of Medical Sciences, P.O Box: 193954763, Tehran, I.R. Iran, Tel: +98 21 22432500; Email: delshad1336@yahoo.com; azizi@endocrine.ac.ir

Submitted: March 01, 2021

Approved: March 09, 2021

Published: March 12, 2021

How to cite this article: Delshad H, Azizi F. Risk of developing eating disorders through the misperception of the body image and the adoption of bad eating habits in a sample of young volleyball athletes. Arch Food Nutr Sci. 2021; 5: 018-026.

DOI: 10.29328/journal.afns. 1001028

Copyright: @ 2021 Delshad H, et al. This is an open access article distributed under the Creative Commons Attribution License, which permits unrestricted use, distribution, and reproduction in any medium, provided the original work is properly cited.

Keywords: lodine deficiency; lodine status; lodine supplementation; Pregnancy

D) Check for updates

OPEN ACCESS

\section{Introduction}

Pregnancy has a profound impact on the thyroid economy and function as it entails. Iodine is considered an essential nutrient. It is required for the synthesis of the growth-regulating thyroid hormones. Growth, neurologic development, reproductive activity, protein synthesis and enzymatic function and many critical metabolic activity are related by thyroid hormones. One of very important their effect is in the development of central nervous system and skeletal system during fetal and infantile periods [1-3]. Iodine is an essential part of thyroid hormones, both thyroxin (T4) and tri-iodothyronin (T3) [4]. Based on age and physiological status, each individual needs between 90 to $290 \mu \mathrm{g}$, mean 150 $\mu \mathrm{g}$, of iodine per day [5]. Iodine sufficiency during pregnancy is extremely important for proper fetal development. During early pregnancy the fetus depends entirely on maternal thyroid hormones and therefore, on maternal iodine intake [6]. After birth, neonates and infants require adequate amount of iodine intake for their proper physical and neurological growth.

In severely iodine deficient areas, pregnancy results in marked hypothyroidism and impairment of fetal neurocognitive development. But adequately powered RCTs are lacking regarding the impact of mild-to-moderate iodine insufficiency on child neurodevelopment. Minor neuropsychological defects have been described in children born to mothers exposed to mild to moderate iodine deficiency during pregnancy and it may subtly affect fetal development $[7,8]$. A meta-analysis of 6,180 mother-child pairs demonstrated that children of mothers with lower iodine status during first trimester of pregnancy, had lower verbal IQ at 1.5 to 8 years of age [9]. This and other studies point to the importance of iodine nutrition for proper fetal development, however, the effects of iodine supplementation during pregnancy on neurodevelopment of offspring are 
not clear. Iodine supplementation of 150 or $200 \mu \mathrm{g}$ per day from early pregnancy to delivery in two separate randomized clinical trials failed to demonstrate any effect on cognitive, language or motor scores of children at ages 1.5 to 2 years $[10,11]$.

\section{Physiological changes of thyroid gland during normal pregnancy}

The normal rise in estrogen during pregnancy induces roughly a doubling in serum thyroid binding globulin (TBG) concentrations, consequently a significant increase in circulating total T4 and T3 levels [12]. The placenta secretes huge amounts of human chorionic gonadotropin (hCG) which acts as a TSH agonist and increases T4 production by approximately 50\% during the first trimester of pregnancy [13]. In normal pregnancy, there is an increase in glomerular filtration rate which is accompanied by an increase kidney clearance of iodine, this physiological change along with increased degradation of T3 and T4 by type 3 deiodinase in the placenta and transfer of iodine to the fetus, increase maternal thyroid demands. Therefore, requirement for iodine nutrition is increased during pregnancy to adopt for thyroid activity of mother and demand of T4 and iodine transfer to the fetus $[6,14]$. In women with iodine deficiency, such adaptive mechanisms fail due to lower intake and stores of iodine [15].

\section{The global burden of iodine deficiency}

The high prevalence of goiter has been noticed during the last century in many parts of the world. In addition, alteration of neuromotor and physical growth during childhood from mild to severe degree (cretinism) were reported in many countries, and all the above findings were related to iodine deficiency disorders (IDD), as named by Hetzel [16]. Worldwide, considerable efforts were planned to overcome IDD in the last century. Iodine Global Network (IGN, a non-profit, nongovernment organization) reports substantial progress in proper iodine nutrition in the majority of countries of the world and demonstrates yearly global scorecard of iodine nutrition in population, using urinary iodine concentration (UIC) of schoolchildren. The most recent score card of IGN [17] shows that 115 countries of the world have optimal iodine intake and only 23 countries remain iodine deficient. It is noteworthy that 14 countries are classified as having iodine excess, which emphasizes the importance of proper monitoring to reduce excess iodine nutrition.

Majority of countries still conduct urinary iodine survey of schoolchildren for monitoring their programs of iodine nutrition, while it has been shown that because of increased iodine demand in pregnancy, iodine deficiency in pregnancy may be seen along with proper iodine nutrition of schoolchildren. In Europe, according to a 2015 estimate, women in approximately two-thirds of countries with available data were iodine deficient during pregnancy [18]. Additionally, a recent systematic review of 13 studies by
Candido, et al. from different regions of the world, including 14,042 pregnant women showed that the prevalence of insufficient iodine status ranged from 16.1 to $84.0 \%$, and the median of iodine intake was insufficient in $75 \%$ of the studies [19]. It is reported that in some iodine sufficient countries like USA, Japan, Iran, Austria, England, Norway, Italy, Sweden and etc. pregnant women are iodine deficient [20-27].

\section{Thyroid hormones and pregnancy outcomes}

Thyroid hormones promote brain development in fetus and neonate and their integrity is critical for fetal growth and some aspects of pregnancy. These effects are mediated through direct actions on maternal and fetal metabolism [28]. The fetus is dependent on the maternal thyroid hormones in the first trimester, therefore, maternal thyroid disarrangement may adversely affect the maturation of the fetal nervous system [29-31]. In addition alteration in the maternal thyroid function may accompany multiple obstetric complications [32,33]. Many cohort studies have focused in the role of derangement in maternal thyroid function on preterm delivery and neonatal birth weight [34-36]. Both overt hypo- and overt hyperthyroidism of pregnant women are associated with a rise in prenatal morbidity and mortality $[37,38]$. However, studies in subclinical thyroid dysfunctions have not shown consistent effects on pregnancy outcomes [38]. Some studies have shown an association between subclinical maternal hypothyroidism and preterm delivery $[29,31]$, while others have not $[39,40]$.

Two studies have found an unexpected inverse relationship between maternal free thyroxin $\left(\mathrm{FT}_{4}\right)$ levels and birth weight $[36,37]$. In a large prospective population-based cohort study in pregnant Spanish women by Gemma León, et al. the influence of maternal thyroid function during early pregnancy on fetal birth weight and preterm delivery has been assessed [41]. The authors found a statistically significant inverse association of TSH and $\mathrm{FT}_{4}$ levels at the first half of pregnancy with birth weight, after adjusting for gestational age and other potential confounding factors. As regards to available data, universal thyroid screening in pregnancy is being undertaken in several countries, although it remains a matter of debate [42].

\section{Thyroid hormones and fetal brain development}

For normal development of fetal brain, thyroid hormones play a critical and essential role. Until the $13^{\text {th }}$ weeks of gestation, fetal thyroid is not developed and fetal source of thyroid hormones comes from the transfer of maternal hormones via the placenta [43]. Thyroid hormone dependent neurodevelopment begins in the second half of the first trimester and includes neuronal proliferation and neuronal migration which will continue into the early part of the second trimester [44]. The second stage of thyroid hormone neurodevelopment includes neurogenesis, neuronal migration, axonal growth, dendritic branching and synaptogenesis, glial cell differentiation and migration, and the onset of myelination [45] (Figure 1). 
Developing brain needs normal level of circulating T4

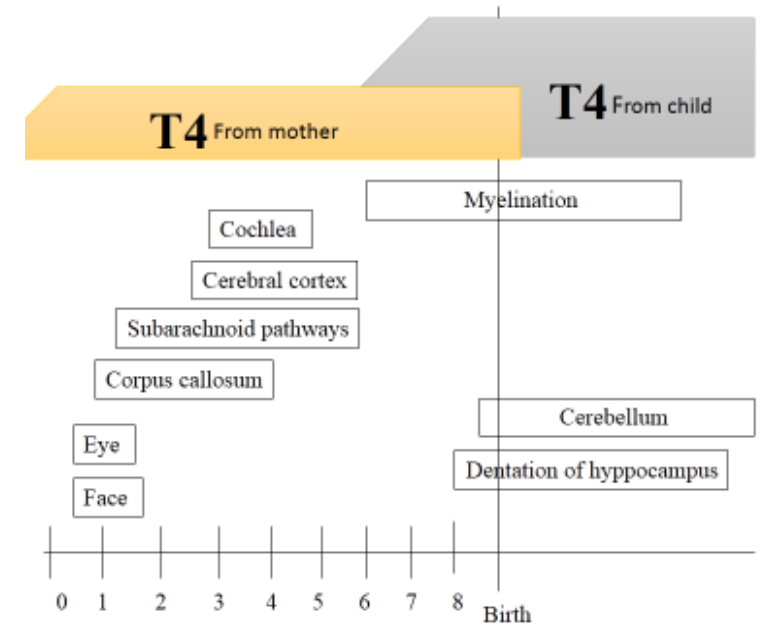

Figure 1: Major events in fetal and neonatal central nervous system development.

\section{Determining iodine deficiency and lodine requirement in pregnancy}

In order to produce enough thyroid hormones to meet fetal requirements, a $50 \%$ increase in iodine intake is recommended during pregnancy and lactation (Table 1) to maintain normal metabolism [46]. The most commonly used index for assessing iodine status in a population is the median urinary iodine concentration (MUIC) as determined from a casual or spot urine sample. UIC measurements as well as the consideration of regional and population differences are of great importance when evaluating and monitoring the effectiveness of fortification programs [47]. A MUIC $>100 \mu \mathrm{g} / \mathrm{L}$ is indicative of adequate iodine status in children, men and non-pregnant women. Based on the WHO recommendation the iodine intake in pregnant and lactating women as measurement of MUIC is regarded as follows: insufficient, below $150 \mu \mathrm{g} / \mathrm{L}$, adequate, $150-249 \mu \mathrm{g} / \mathrm{L}$, more than adequate, $250-499 \mu \mathrm{g} / \mathrm{L}$, excessive, $500 \mu \mathrm{g} / \mathrm{L}$ [48].

Many international societies and organizations, including WHO recommend iodine supplementations for pregnant women in order to meet the increased iodine requirement of pregnant women, in particular in areas of iodine deficiency [49]. However, available data from observational and clinical trials do not provide meaningful conclusions regarding effectivity and safety of iodine supplementation for all pregnant women [50]. Only in women with severe iodine

Table 1: lodine requirement in pregnancy and lactation $(\mu \mathrm{g} /$ day)

\begin{tabular}{|c|c|}
\hline During Pregnancy & \\
\hline Basal & 150 \\
\hline $40 \%-50 \%$ increased T4 requirements & $50-100$ \\
\hline Transfer of T4 and iodine from mother to fetus & 50 \\
\hline Increased renal clearance of iodine & $?$ \\
\hline Total & $250-300$ \\
\hline During Lactation & 150 \\
\hline Basal & $75-200$ \\
\hline $0.5-1.1 \mathrm{~L}$ milk/day $\times 150-180 \mu \mathrm{g}$ iodine $/ \mathrm{L}$ & $225-350$ \\
\hline Total & \\
\hline
\end{tabular}

deficiency, iodine supplementation shows a reduction in the risk of hypothyroidism. If needed, iodine supplementation should be implemented before conception, in order to protect fetal brain from unwanted effects of iodine deficiency [51]. But from a public health and epidemiological perspective, it should be considered that immigrating women with a low income or without access to the public health system have a poor adherence both to the salt iodization policy and iodine supplements in preconception and pregnancy. Their intake of iodine-rich-foods also is limited. The identification of barriers to health care access could be useful to promote specific health interventions in this target population [52].

\section{lodine deficiency and pregnancy outcomes}

It is now well established that iodine deficiency of pregnant woman could be potentially associated with both maternal and fetal adverse outcomes [53]. Severe iodine deficiency is associates with preterm labor, gestational hypertension, pregnancy loss and gestational diabetes. In addition, small gestational age and impaired fetal neurodevelopment may occur with very poor iodine nutrition.

The first report of the association between iodine deficiency and stillbirth/abortion dates back to 1939 [54]. Two decades ago a study published in 2000 from West Africa, showed that severe iodine deficiency was associated with increased risk of stillbirths or recurrent miscarriages [55]. In a prospective cohort study published in 2018 from Henan Province of China, it has been shown that the rates of preeclampsia, placenta Previa and fetal distress was lower among pregnant women with iodine sufficiency (UIC $150-249 \mu \mathrm{g} / \mathrm{L}$ ) than those women with severe iodine deficiency (UIC $<50 \mu \mathrm{g} / \mathrm{L}$ ) [56]. In contrast to these findings, some recent evidence has shown that there is no association of severe iodine deficiency with some adverse materno-fetal outcomes. In the LIFE prospective cohort study, the risk of pregnancy loss was not elevated in women with severe iodine deficiency compared to the iodine sufficient group [57]. Similarly in ALSPAC study [58] the incidence of materno-fetal outcomes were not significantly different among severely iodine deficient pregnant women (UIC $<50 \mu \mathrm{g} / \mathrm{L}$ ) compared to the iodine sufficient group. Another frequently attributed impact of severe iodine deficiency before and during pregnancy is increased rates of goiter, thyroid nodules formation $[59,60]$ and the induction of maternal hypothyroxinemia [61]. A few clinical studies indicate that iodine supplementation during pregnancy reduces maternal thyroid size [62] and the risk of maternal hypothyroxinemia $[63,64]$. In contrast to the potential effects of severe iodine deficiency on pregnancy outcomes, the potential impact of mild-to-moderate iodine deficiency on fertility and pregnancy outcomes remains largely unknown [65]. A few studies have investigated associations between iodine status and risk of adverse pregnancy outcomes in mild-to-moderate iodine deficiency [66,67]. 
For birth weight, some studies have reported reduced birth weight in mild-to-moderate iodine deficiency $[68,69]$. In a population-based cohort study it has been shown that even mild-to-moderate iodine deficiency may affect thyroid function in pregnant women and leads to adverse pregnancy outcomes [70] however a systematic review reported no evidence of the effect of salt iodization or iodine supplement on prenatal growth in mild-to-moderate iodine deficiency [71]. Recently the last Norwegian Mother, Father and Child Cohort Study [72] has shown that a low iodine intake was associated with restricted fetal growth and a higher prevalence of preeclampsia in women with mild-tomoderate iodine deficiency. Results also indicated increased risk of sub-fecundity and preterm delivery. The result of this study and other studies indicate that any necessary iodine supplementation should be initiated before pregnancy to achieve adequate iodine intake before conception, because of susceptibility of the fetal brain to iodine deficiency [73].

\section{lodine deficiency and neurodevelopment of offspring}

Iodine plays a very important role in neurodevelopment and organogenesis of human fetus [74]. From the beginning of embryon until 16-20 weeks of gestation, the fetus is depended on the supply of maternal thyroid hormones. Conversion of maternal T4 to T3 via placental deiodination produces adequate amount of FT3 for fetal neurodevelopment. Binding of T3 to neuronal cell receptor activates the transcription and expression of genes involved in neurodevelopment, such as myelination, cell migration and synapse formation [75,76]. Thus, fetal development is dependent on adequate thyroid hormone, and maternal hypothyroidism is associated with serious and irreversible fetal and offspring damages.

In 1960s, a large trial of 165,000 people in Papua New Guinea pointed to the importance of adequate dietary iodine in prevention of cretinism [77]. Injection of iodized oil before conception or in early pregnancy in women with severe iodine deficiency decreased the incidence of cretinism and improve cognition and psychomotor development of children, compared to placebo control group. Late on, another study in China showed that in a remote province with endemic cretinism, iodized oil given early in pregnancy improved cognitive outcomes, compared to those given iodine later in pregnancy [78]. Results from animal studies and observational human studies indicate that maternal mild-to-moderate iodine deficiency also may affect working memory and auditory processing speed and may negatively affect fetal neurodevelopment such as reduced IQ, school performance, language delay, and behavior problems. This concept has been examined in the Avon Longitudinal Study of Parents and Children (ALSPAC) cohort. Children of women with a MUIC less than $150 \mu \mathrm{g} / \mathrm{L}$ were more likely to have scores in the lowest quartile for verbal IQ, reading accuracy, and reading comprehension than were those of mothers with MUIC $150 \mu \mathrm{g} / \mathrm{L}$ or more [79]. Similar findings have been observed by Hynes, et al. in Tasmania [80]. Mild gestational iodine deficiency also has subtle negative impacts on language skills. Abel, et al. in Norwegian Mother and Child Cohort Study $(\mathrm{MoBa})$, have shown the language delay and poorer school performance in children of mothers with inadequate iodine intake during pregnancy [81]. In another study, Markhus, et al concluded that an insufficient iodine intake in pregnancy was associated with lower infant language skills up to 18 months [82]. Although a causal relation has not confirmed in a RCT by Gowachirapant, et al. [10].

\section{Interventional studies}

Nowadays, severe iodine deficiency is rare, but mildto-moderate iodine deficiency, particularly in pregnant women, is prevalent [83]. Many studies on the effect of iodine supplementation on maternal and newborn thyroid functions, neurodevelopment of infants and schoolchildren cognitive performance have been performed in the last three decades [84-86]. These studies have not shown constant association between iodine supplementation and pregnancy outcomes [87]. Numerous experimental, epidemiologic and animal studies have demonstrated the association between maternal thyroid function in pregnancy and cognition and psychomotor development of offsprings. In a study Chaouki, et al. treated Algerian pregnant women with oral iodized oil just before conception or during the first trimester. This intervention significantly increased placental and birth weights in a region of endemic goiter area [88]. The same study reported that in the treated group the rates of abortion ( $0 \%$ vs. $14.0 \%)$, prematurity (10.8\% vs. $14.3 \%)$ and stillbirth $(9.0 \%$ vs. $20.4 \%)$ were significantly lower than in the untreated group. In a study by Velasco, et al. the psychological development of infants was evaluated at aged 3 to 18 months whose mothers had received $300 \mu \mathrm{g}$ of potassium iodide during the first trimester of their pregnancy and compared with infants of control mothers with no iodine supplementation. Children of iodine supplemented group had a more favorable psychometric assessment than control group [86]. This study highlighted that dietary iodine supplements not only have no harmful effect on the neurodevelopment of the children, they may even be beneficial. In another study Qian, et al. in a meta-analysis of 37 studies involving 12292 children, have shown that those children whom mothers were supplemented with iodine before and during pregnancy, had more Intelligent Quotient (IQ) than those without iodine supplementation [89]. In a randomized placebo-controlled trial by Simona Censi, et al. it has been shown that initial iodine supplementation of $225 \mu \mathrm{g} /$ day in pregnant women from the first trimester helps to prevent thyroid derangement and may avoid detrimental impact of mild-to-moderate iodine deficiency on fetal neurodevelopment [90]. A systematic review of nine randomized controlled trials (RCTs) by Taylor, et al. [91] has shown that in seven RCTs iodine treatment was associated with a significant increase in maternal urinary iodine excretion. Rebagliato, et al. in their observational study of mildly iodine deficient women, found 
that iodine supplementation with at least $150 \mu \mathrm{g} /$ day, did not improve psychomotor or mental development of their offspring [92]. Recently in a RCT by Mohammed, et al. from Ethiopia, it has been shown that iodized salt intervention improved the iodine status of pregnant women and their children [93]. The last available systemic review and metaanalysis of 37 publications -10 RCTs, 4 non-RCT intervention and 23 observational studies- has assessed the available evidence on the effects of iodine supplementation on thyroid function and child neurodevelopment in mildly-to-moderately iodine-deficient pregnant women [94]. Most of these studies showed no effect on maternal or infant TSH or FT4. Overall there was a lack of data on child cognitive outcomes. In metaanalysis of two RCTs no effect on child cognitive or motor scores was demonstrated. This review and meta-analysis provides insufficient good-quality evidence to support current recommendations for iodine supplementation of pregnant women in areas of mild-to-moderate iodine deficiency.

In conclusion, available data have shown that correction of maternal mild-moderate iodine deficiency may improve neurological development of offspring. It is noteworthy that there exist a lack of randomized, controlled trials in this area. Due to the lack of data from any RCTs, several medical and public health advisory groups recommendations to initiate iodine supplementation for pregnant and lactating women or those who are planning a pregnancy have not been widely adopted to date in most regions.

\section{Risks of iodine supplementation}

Thyroid of human fetus attain the ability to fully scape from the acute Wolff-Chaikoff effect only at 32 weeks of gestation. Therefore, fetal hypothyroidism may develop after large iodine exposure, even no alterations in maternal thyroid function is observed [95]. It has been recommended to keep oral iodine replacement to less than $500 \mu$ g daily during pregnancy [96]. A study showed that the odds of subclinical hypothyroidism is increased in pregnant women with UIC of $250-499 \mu \mathrm{g} / \mathrm{L}$, compare to those with UIC of 150 - $250 \mu \mathrm{g} / \mathrm{L}$ [97]. This rose to an odds ratio of 2.17 in pregnant women with a UIC $>500 \mu \mathrm{g} / \mathrm{L}$. Furthermore, individuals with a UIC $>500 \mu \mathrm{g} / \mathrm{L}$ also had a 2.85 fold increase in odds of isolated hypothyroxinemia. Data from the INMA cohort $(\mathrm{N}=1519)$ showed that children of mothers who consumed $150 \mu \mathrm{g} /$ day or more of iodine had higher odds of lower psychomotor scores (OR $=1.5 ; 95 \% \mathrm{CI} 0.8,2.9)$ and an IQ score less than 85 (OR $=1.7 ; 95 \% \mathrm{CI} 0.9,3.0)$. This study also indicates that supplementary iodine intake in excess of $200 \mu \mathrm{g} /$ day was associated with higher TSH compared with those supplemented with less than $200 \mu \mathrm{g} /$ day [84]. Another study demonstrated that a sudden increase in iodine intake of pregnant women may temporary inhibit thyroid hormone production and cause lower availability of T4 to the fetus [88].

The Institute of Medicine recommends an iodine upper limit of $1100 \mu \mathrm{g} /$ day during pregnancy [98]. The data from a cross-sectional study conducted in China [96] suggest that the Institute of Medicine's recommended $1100 \mu \mathrm{g} /$ day upper limit is too high, therefore the WHO more conservatively recommends an upper limit of $500 \mu \mathrm{g} /$ day [99]. Different clinical trials on iodine supplementation of pregnant women around the worlds, indicate that daily iodine supplementation with 50 to $300 \mu$ g iodine among pregnant women with moderate iodine deficiency was not associated with any adverse outcomes [100-104]. Ideally, women should have adequate intra-thyroidal iodine stores before conception, which should be assured by universal salt iodization (UIC) programs. In 2006 American Thyroid Association (ATA) recommended that all pregnant women should receive at least $150 \mu \mathrm{g}$ iodine daily as dietary supplement [105]. But WHO [106], UNICEF [107] and ICCIDD (recently named Iodine Global Network =IGN) [108] underline that strategies to control iodine deficiency in pregnant and lactating women should be modulated according to the iodine nutritional status of the population. These organizations do not recommend iodine-containing supplements in pregnant women living in areas where universal salt iodization has been effective for at least two years. According to new guidelines of both the ATA [109], and Endocrine Society [110], all pregnant women should ingest $250 \mu \mathrm{g}$ iodine daily and, to achieve this optimal intake, women who are planning pregnancy or currently pregnant should supplement their diet with a daily oral supplement that contains $150 \mu \mathrm{g}$ of iodine. Both WHO and scientific societies agree on a daily iodine intake during pregnancy of $250 \mu \mathrm{g} /$ day, but due to lack of randomized controlled trials in this area, there is no consensus on universal iodine supplementation in pregnancy. The discordance in guidance from different authorities most likely reflects the lack of data to properly indicate when and which dosage of iodine to recommend in pregnancy.

\section{Conclusion}

The physiological adaptation of maternal thyroid occurs in the first trimester to compensate the increased thyroid hormone requirement during pregnancy. Association between maternal hypothyroidism with poor pregnancy outcomes and impaired cognitive and psychomotor in offspring are well documented. In addition, subclinical hypothyroidism may also be associated with gestational hypertension, preeclampsia, abortion, fetal growth retardation, neonatal morbidity and perinatal mortality. Adequate iodine nutrition during pregnancy and lactation is vital for thyroid hormone synthesis. Therefore, all women during pregnancy and lactation need optimal iodine intake. Iodine prophylaxis and prevention of iodine deficiency during pregnancy and lactation may decrease the rates of fetal death, endemic cretinism, neurocognitive impairment and prevent mental retardation of children. There are also many studies and systematic reviews that indicate even mild to moderate iodine deficiency may disturb thyroid function in pregnancy and it also may affects working memory and auditory processing speed and may negatively affect fetal neurodevelopment such as reduced IQ, school performance, 
language delay, and behavior problems. The benefits of correcting mild-to-moderate iodine deficiency are unclear and demand further controlled trial. Many international organization recommend that supplementation in pregnancy should be used in countries with mild-to-moderate iodine deficiency, although other organizations recommend that all pregnant and breastfeeding women should take at least 150 $\mu$ g iodine supplementation, not only in iodine deficient regions but also in iodine sufficient areas. With referring to the lack of universal consensus and existing controversy regarding the adverse effects of mild-to moderate iodine deficiency during pregnancy on mother and sibling wellbeing and outcomes, we recommend to perform further prospective randomized controlled trials in this field.

\section{Ethical statement}

The manuscript is currently being considered for publication has not been published in whole or in part in another journals.

\section{References}

1. Brent GA. Mechanisms of thyroid hormone action. J Clin Invest. 2012; 122: 3035

PubMed: https://pubmed.ncbi.nlm.nih.gov/22945636/

2. Mendoza A, Hollenberg AN. New insights into thyroid hormone action. Pharmacol Ther. 2017; 173: 135-145.

PubMed: https://pubmed.ncbi.nlm.nih.gov/28174093/

3. Flamant F, Cheng SY, Hollenberg AN, Moeller LC, Samarut J, et al Thyroid Hormone Signaling Pathways: Time for a More Precise Nomenclature. Endocrinology. 2017; 158: 2052-2057.

PubMed: https://pubmed.ncbi.nlm.nih.gov/28472304/

4. Zimmermann MB. lodine deficiency. Endocr Rev. 2009; 30: 376-408. PubMed: https://pubmed.ncbi.nlm.nih.gov/19460960/

5. Institute of Medicine, Food and Nutrition Board. Dietary Reference Intakes for Vitamin A, Vitamin K, Arsenic, Boron, Chromium, Copper lodine, Iron, Manganese, Molybdenum, Nickel, Silicon, Vanadium, and Zinc. Washington, DC: National Academy Press, 2001. PubMed: https://pubmed.ncbi.nlm.nih.gov/25057538/

6. Delange $F$. lodine requirements during pregnancy, lactation and the neonatal period and indicators of optimal iodine nutrition. Public Health Nutr. 2007; 12A: 1571-1580.

PubMed: https://pubmed.ncbi.nlm.nih.gov/18053281/

7. Lombardi FAA, Pinchera A, Antonangeli L, Rago $T$, Chiovato $L$, et al. Mild iodine deficiency during fetal/neonatal life and neuropsychological impairment in Tuscany. J Endocrinol Invest. 1995; 18: 57-62. PubMed: https://pubmed.ncbi.nlm.nih.gov/7759786/

8. van Mil NH, Tiemeier H, Bongers-Schokking JJ, Ghassabian, Hofman A et al. Low urinary iodine excretion during early pregnancy is associated with alterations in executive functioning in children. J Nutr. 2012; 142 2167-2174.

https://pubmed.ncbi.nlm.nih.gov/23077186/

9. Levie D, Korevaar TIM, Bath SC, Murcia M, Dineva M, et al. Association of maternal iodine status with child IQ: A meta-analysis of individual participant data. J Clin Endocrinol Metab. 2019; 104: 5957-5967. PubMed: https://pubmed.ncbi.nlm.nih.gov/30920622/

10. Gowachirapant S, Jaiswal N, Melse-Boonstra A, Galetti V, Stinca S, et al. Effect of iodine supplementation in pregnant women on child neurodevelopment: A randomized, double-blind, placebo-controlled trial. Lancet Diabetes Endocrinol. 2017; 5: 853-863.

PubMed: https://pubmed.ncbi.nlm.nih.gov/29030199/
11. Zhou SJ, Skeaff SA, Ruan P, Doyle LW, Anderson PJ, et al. The effect of iodine supplementation in pregnancy on early childhood neurodevelopment and clinical outcomes: Results of an aborted randomized placebo-controlled trial. Trials. 2015; 16: 563.

PubMed: https://pubmed.ncbi.nlm.nih.gov/26654905/

12. Fantz CR, Dagogo-Jack S, Ladenson JH, Gronowski AM. Thyroid function during pregnancy. Clin Chem. 1999; 45: 2250-2258. PubMed: https://pubmed.ncbi.nlm.nih.gov/10585360/

13. Ballabio M, Poshychinda M, Ekins RP. Pregnancy-induced changes in thyroid function: role of human chorionic gonadotropin as putative regulator of maternal thyroid. J Clin Endocrinol Metab. 1991; 73: 824-831. PubMed: https://pubmed.ncbi.nlm.nih.gov/1909707/

14. Glinoer $\mathrm{D}$. The regulation of thyroid function during normal pregnancy: importance of the iodine nutrition status. Best Pract Res Clin Endocrinol Metab. 2004; 18: 133-152.

PubMed: https://pubmed.ncbi.nlm.nih.gov/15157832/

15. Leung AM, Pearce EN, Braverman LE. lodine nutrition in pregnancy and lactation. Endocrinol Metab Clin North Am. 2011; 40: 765-777. PubMed: https://pubmed.ncbi.nlm.nih.gov/22108279/

16. Hetzel BS. lodine deficiency disorders (IDD) and their eradication. Lancet. 1983; 2: 1126-1129.

PubMed: https://pubmed.ncbi.nlm.nih.gov/6138653/

17. lodine Global Network. Global Scorecard 2020. https://www.ign.org/ cm_data/Global-Scorecard-2020-3-June-2020.pdf

18. Zimmermann MB, Gizak M, Abbott K, Andersson M, Lazarus JH. lodine deficiency in pregnant women in Europe. Lancet Diabetes Endocrinol. 2015; 3: 672-674.

PubMed: https://pubmed.ncbi.nIm.nih.gov/26268907/

19. Candido AC, Morais NS, Dutra LV, Pinto CA, Franceschini SDCC, et al Insufficient iodine intake in pregnant women in different regions of the world: a systematic review. Arch Endocrinol Metab. 2019; 63: 306-311. PubMed: https://pubmed.ncbi.nlm.nih.gov/31340241/

20. Perrine CG, Herrick KA, Gupta PM, Caldwell KL. Iodine Status of Pregnant Women and Women of Reproductive Age in the United States Thyroid. 2019; 29: 153-154.

PubMed: https://pubmed.ncbi.nlm.nih.gov/30351199/

21. Fuse $Y$, Shishiba $Y$, Irie $M$. Gestational changes of thyroid function and urinary iodine in thyroid antibody-negative Japanese women. Endocr J. 2013; 60; 1095-1106.

PubMed: https://pubmed.ncbi.nlm.nih.gov/23811988/

22. Delshad H, Touhidi M, Abdollahi Z, Hedayati M, Salehi F, et al. Inadequate iodine nutrition of pregnant women in an area of iodine sufficiency. J Endocrinol Invest. 2016; 39: 755-762.

PubMed: https://pubmed.ncbi.nlm.nih.gov/26951055/

23. Lindorfer H, Krebs M, Kautzky-Willer A, Bancher-Todesca D, Sager M, et al. lodine deficiency in pregnant women in Austria. Eur J Clin Nutr. 2015; 69: 349-354.

PubMed: https://pubmed.ncbi.nlm.nih.gov/25491497/

24. Knight BA, Shields BM, He X, Pearce EN, Braverman LE, et al. lodine deficiency amongst pregnant women in South-West England. Clin Endocrinol (Oxf). 2017; 86: 451-455.

PubMed: https://pubmed.ncbi.nlm.nih.gov/27805280/

25. Henjum S, Aakre I, Lilleengen AM, Garnweidner-Holme L, Borthne S, et al. Suboptimal lodine Status among Pregnant Women in the Oslo Area, Norway. Nutrients. 2018; 10: 280.

PubMed: https://pubmed.ncbi.nlm.nih.gov/29495606/

26. Tuccilli C, Baldini E, Truppa E, D'Auria B, De Quattro D, et al. lodine deficiency in pregnancy: Still a health issue for the women of Cassino city, Italy. Nutrition. 2018; 50: 60-65.

PubMed: https://pubmed.ncbi.nlm.nih.gov/29529424/

27. Manousou S, Andersson M, Eggertsen R, Hunziker S, Hulthén L, et al. lodine deficiency in pregnant women in Sweden: a national cross- 
sectional study. Eur J Nutri. 2020; 59: 2535-2545.

PubMed: https://pubmed.ncbi.nlm.nih.gov/31616973/

28. Chan S, Kachilele S, McCabe CJ, et al. Early expression of thyroid hormone deiodinases and receptors in human fetal cerebral cortex. Brain Res Dev Brain Res. 2002; 138: 109-116.

PubMed: https://pubmed.ncbi.nlm.nih.gov/12354639/

29. Forhead AJ, Fowden AL. Thyroid hormones in fetal growth and prepartum maturation. J Endocrinol. 2014; 221: R87-R103.

PubMed: https://pubmed.ncbi.nlm.nih.gov/24648121/

30. Haddow JE, Palomaki GE, Allan WC, Williams JR, Knight GJ, et al Maternal thyroid deficiency during pregnancy and subsequent neuropsychological development of the child. New Engl J Med. 1999; 341:549-555.

PubMed: https://pubmed.ncbi.nlm.nih.gov/10451459/

31. Pop VJ, Brouwers EP, Vader HL, Vulsma T, van Baar AL, et al Maternal hypothyroxinaemia during early pregnancy and subsequent child development: a 3-year follow-up study. Clin Endocrinol (Oxf). 2003; 59:282-288.

PubMed: https://pubmed.ncbi.nlm.nih.gov/12919150/

32. Allan WC, Haddow JE, Palomaki GE, Williams JR, Mitchell ML, et al. Maternal thyroid deficiency and pregnancy complications: implications for population screening. J Med Screen. 2000; 7: 127-130.

PubMed: https://pubmed.ncbi.nlm.nih.gov/11126160/

33. Casey BM, Dashe JS, Wells CE, McIntire DD, Byrd W, et al. Subclinical hypothyroidism and pregnancy outcomes. Obstet Gynecol. 2005; 105 239-245.

PubMed: https://pubmed.ncbi.nlm.nih.gov/15684146/

34. Korevaar TI, Schalekamp-Timmermans S, de Rijke YB, et al. Hypothyroxinemia and TPO-antibody positivity are risk factors for premature delivery: the Generation R Study. J Clin Endocrinol Metab. 2013; 98: 4382-4390.

PubMed: https://pubmed.ncbi.nlm.nih.gov/24037884/

35. Stagnaro-Green A, Chen X, Bogden JD, Davies TF, Scholl TO. The thyroid and pregnancy: a novel risk factor for very preterm delivery. Thyroid. 2005; 15: 351-357.

PubMed: https://pubmed.ncbi.nlm.nih.gov/15876159/

36. Shields BM, Knight BA, Hill A, Hattersley AT, Vaidya B. Thyroid hormone level at birth is associated with fetal growth. J Clin Endocrinol Metab. 2011; 96: E934-E938.

PubMed: https://www.ncbi.nlm.nih.gov/pmc/articles/PMC3100744/

37. Medici M, Timmermans S, Visser W, de Muinck Keizer-Schrama S, Jaddoe $\mathrm{V}$, et al. Maternal thyroid hormone parameters during early pregnancy and birth weight: the Generation R Study. J Clin Endocrinol Metab. 2013; 98:59-66.

PubMed: https://pubmed.ncbi.nlm.nih.gov/23150694/

38. Casey BM, Leveno KJ. Thyroid disease in pregnancy. Obstetr Gynecol. 2013; 108: 1283-1292.

PubMed: https://pubmed.ncbi.nlm.nih.gov/17077257/

39. Männistö $T$, Vääräsmäki $M$, Pouta $A$, Hartikainen $A L$, Ruokonen, et al. Perinatal outcome of children born to mothers with thyroid dysfunction or antibodies: a prospective population-based cohort study. J Clin Endocrinol Metab. 2009; 94: 772-779.

PubMed: https://pubmed.ncbi.nlm.nih.gov/19106271/

40. Sahu MT, Das V, Mittal S, Agarwal A, Sahu M. Overt and subclinical thyroid dysfunction among Indian pregnant women and its effect on maternal and fetal outcome. Arch Gynecol Obstet. 2010; 281: 215-220. PubMed: https://pubmed.ncbi.nlm.nih.gov/19437026/

41. León G, Murcia M, Rebagliato M, Álvarez-Pedrerol M, Castilla, et al. Maternal thyroid dysfunction during gestation, preterm delivery, and birth weight. The Infancia y Medio Ambiente Cohort, Spain Paediatr Perinat Epidemiol. 2015; 29: 113-122.

PubMed: https://pubmed.ncbi.nlm.nih.gov/25565408/

42. Taylor PN, Lazarus JH. Hypothyroidism in Pregnancy. Endocrinol
Metab Clin North Am. 2019; 48: 547-556.

PubMed: https://pubmed.ncbi.nlm.nih.gov/31345522/

43. Patel J, Landers K, Li H, Mortimer RH, K Richard. Thyroid hormones and fetal neurological development. J Endocrinol. 2011; 209: 1-8. PubMed: https://pubmed.ncbi.nlm.nih.gov/21212091/

44. Kester MH, de Mena RM, Obregon MJ. lodothyronine levels in the human developing brain: major regulatory roles of iodothyronine deiodinases in different areas. J Clin Endocrinol Metab. 2004; 89: 3117-3128.

PubMed: https://pubmed.ncbi.nlm.nih.gov/15240580/

45. Morreale de Escobar G, Obregon MJ, Escobar del Ray F. Maternal thyroid hormones early in pregnancy and fetal brain development. Best Pract Res Clin Endocrinol Metab. 2004; 18: 225-248. PubMed: https://pubmed.ncbi.nlm.nih.gov/15157838/

46. Fisher DA, Polk DH. Development of the thyroid. Baillieres Clin Endocrinol Metab. 1989; 3: 627-657.

PubMed: https://pubmed.ncbi.nlm.nih.gov/2698148/

47. Ittermann T, Albrecht $\mathrm{D}$, Arohonka $\mathrm{P}$, Bilek R, J. de Castro J. Standardized Map of lodine Status in Europe. Thyroid. 2020; 30: 1346-1354.

PubMed: https://pubmed.ncbi.nlm.nih.gov/32460688/

48. WHO Secretariat, Andersson M, de Benoist B, Delange F, Zupan J. Prevention and control of iodine deficiency in pregnant and lactating women and in children less than 2-years-old: conclusions and recommendations of the Technical Consultation. Public Health Nutr. 2007; 10: 1606-1611.

PubMed: https://pubmed.ncbi.nlm.nih.gov/18053287/

49. WHO/UNICEF. Reaching optimal iodine nutrition in pregnant and lactating women and young children. Joint Statement by the WHO and the UNICEF. World Health Organization, Geneva. 2007.

50. Pearce EN, Lazarus JH, Moreno-Reyes R, Zimmermann MB. Consequences of iodine deficiency and excess in pregnant women: an overview of current knowns and unknowns. Am J Clin Nutr. 2016; 104: 918s-923s.

PubMed: https://pubmed.ncbi.nlm.nih.gov/27534632/

51. Zhou SJ, Anderson AJ, Gibson RA, Makrides M. Effect of iodine supplementation in pregnancy on child development and other clinical outcomes: a systematic review of randomized controlled trials. Am J Clin Nutrit. 2013; 98: 1241-1254.

PubMed: https://pubmed.ncbi.nIm.nih.gov/24025628/

52. Magri F, Zerbini F, Gaiti M, Capelli V, Croce, S, et al. Poverty and immigration as a barrier to iodine intake and maternal adherence to iodine supplementation. J Endocrinol Invest. 2019; 42: 435-442. PubMed: https://pubmed.ncbi.nIm.nih.gov/30132288/

53. Berg V, Nost TH, Skeie G, Thomassen Y, Berlinger B, et al. Thyroid homeostasis in mother-child pairs in relation to maternal iodine status: the MISA study. Eur J Clin Nutr. 2017; 71: 1002-1007.

PubMed: https://pubmed.ncbi.nlm.nih.gov/28537582/

54. Kemp WN. lodine deficiency in relation to the stillbirth problem. Can Med Assoc J. 1939; 41: 356-361.

PubMed: https://pubmed.ncbi.nlm.nih.gov/20321492/

55. Dillon JC, Milliez J. Reproductive failure in women living in iodine deficient areas of West Africa. BJOG. 2000; 107: 631-636.

PubMed: https://pubmed.ncbi.nlm.nih.gov/10826578/

56. Yang J, Liu Y, Liu H, Zheng $\mathrm{H}$, Li X, et al. Associations of maternal iodine status and thyroid function with adverse pregnancy outcomes in Henan Province of China. J Trace Elem Med Biol. 2018; 47: 104-110. PubMed: https://pubmed.ncbi.nlm.nih.gov/29544795/

57. Mills JL, Ali M, Buck Louis GM, Kannan K, Weck J, et al. Pregnancy loss and iodine status: the LIFE prospective cohort study. Nutrients. 2019; 11: 534

PubMed: https://pubmed.ncbi.nlm.nih.gov/30823683/ 
58. Bath SC, Steer CD, Golding J, Emmett P, Rayman MP. Effect of inadequate iodine status in UK pregnant women on cognitive outcomes in their children: results from the Avon Longitudinal Study of Parents and Children (ALSPACE). Lancet. 2013; 382: 331-337.

PubMed: https://pubmed.ncbi.nlm.nih.gov/23706508/

59. Smyth PP, Hetherton AM, Smith DF, Radcliff M, O'Herlihy C. Maternal iodine status and thyroid volume during pregnancy: correlation with neonatal iodine intake. J Clin Endocrinol Metab. 1997; 82: 2840-2843. PubMed: https://pubmed.ncbi.nlm.nih.gov/9284707/

60. Sahin SB, Ogullar S, Ural UM, Ilkkilic K, Metin Y, (2014) Alterations of thyroid volume and nodular size during and after pregnancy in a severe iodine-deficient area. Clin Endocrinol. 81: 762-768.

PubMed: https://pubmed.ncbi.nlm.nih.gov/24811142/

61. Glinoer D. Clinical and biological consequences of iodine deficiency during pregnancy. Endocr Dev. 2007; 10: 62-85.

PubMed: https://pubmed.ncbi.nlm.nih.gov/17684390/

62. Liesenkotter KP, Gopel W, Bogner U, Stach B, Gruters A. Earliest prevention of endemic goiter by iodine supplementation during pregnancy. Eur J Endocrinol. 1996; 134: 443-448.

PubMed: https://pubmed.ncbi.nlm.nih.gov/8640295/

63. Moleti M, Lo Presti VP, Campolo MC, Mattina F, Galletti M, et al. lodine prophylaxis using iodized salt and risk of maternal thyroid failure in conditions of mild iodine deficiency. J Clin Endocrinol Metab. 2008; 93: 2616-2621.

PubMed: https://pubmed.ncbi.nlm.nih.gov/18413422/

64. Moleti M, Di Bella B, Giorgianni G, Mancuso A, De Vivo A, et al. Maternal thyroid function in different conditions of iodine nutrition in pregnant women exposed to mild-moderate iodine deficiency: an observational study. Clin Endocrinol. 2011; 74: 762-768.

PubMed: https://pubmed.ncbi.nlm.nih.gov/21521276/

65. Zimmermann MB. The role of iodine in human growth and development. Semin Cell Dev Biol. 2011; 22: 645-652.

PubMed: https://pubmed.ncbi.nlm.nih.gov/21802524/

66. Snart CJP, Keeble C, Taylor E, Cade JE, Stewart PM, et al. Maternal iodine status and associations with birth outcomes in three major cities in the United Kingdom. Nutrients. 2019; 11: 441.

PubMed: https://pubmed.ncbi.nlm.nih.gov/30791590/

67. Charoenratana C, Leelapat P, Traisrisilp K, Tongsong T. Maternal iodine insufficiency and adverse pregnancy outcomes. Matern Child Nutr. 2015; 12: 680-687.

PubMed: https://pubmed.ncbi.nlm.nih.gov/26332721/

68. Alvarez-Pedrerol M, Guxens M, Mendez M, Canet $Y$, Martorell R, et al. lodine levels and thyroid hormones in healthy pregnant women and birth weight of their offspring. Eur J Endocrinol. 2009; 160: 423-429. PubMed: https://pubmed.ncbi.nlm.nih.gov/19114540/

69. Abel MH, Korevaar TIM, Erlund I, Villanger GD, Caspersen IH, et al lodine intake is associated with thyroid function in mild to moderately iodine deficient pregnant women. Thyroid. 2018; 28: 1359-1371. PubMed: https://pubmed.ncbi.nlm.nih.gov/30132420/

70. Levie D, Derakhshan A, Shu H, Broeren M, de Poortere R, et al. The association of maternal iodine status in early pregnancy with thyroid function in the SELMA study. Thyroid. 2019; 29: 1660-1668. PubMed: https://pubmed.ncbi.nlm.nih.gov/31524090/

71. Farebrother J, Naude CE, Nicol L, Sang Z, Yang Z, et al. Effects of lodized Salt and lodine Supplements on Prenatal and Postnatal Growth: A Systematic Review. Adv Nutr. 2018; 9: 219-237. PubMed: https://pubmed.ncbi.nlm.nih.gov/29767700/

72. Abel MH, Caspersen IH, Sengpiel V. Insufficient maternal iodine intake is associated with sub-fecundity, reduced fetal growth, and adverse pregnancy outcomes in the Norwegian Mother, Father and Child Cohort Study BMC Med. 2020; 18: 211.

PubMed: https://pubmed.ncbi.nlm.nih.gov/32778101/

73. Lazarus J, Brown RS, Daumerie C, Hubalewska-Dydejczyk A,
Negro R, et al. 2014 European thyroid association guidelines for the management of subclinical hypothyroidism in pregnancy and in children. Eur Thyroid J. 2014; 3: 76-94.

PubMed: https://pubmed.ncbi.nlm.nih.gov/25114871/

74. Moog NK, Entringer S, HeimC,Wadhwa PD, Kathmann N, Buss C. Influence of maternal thyroid hormones during gestation on fetal brain development. Neuroscience. 2017; 342: 68-100.

PubMed: https://pubmed.ncbi.nlm.nih.gov/26434624/

75. Mohan V, Sinha RA, Pathak A, Rastogi L, Kumar P, et al. Maternal thyroid hormone deficiency affects the fetal neocorticogenesis by reducing the proliferating pool, rate of neurogenesis and indirect neurogenesis. Exp Neurol. 2012; 237: 477-488.

PubMed: https://pubmed.ncbi.nlm.nih.gov/22892247/

76. Pop VJ, Kuijpens JL, van Baar AL, Verkerk G, van Son MM, et al. Low maternal free thyroxin concentrations during early pregnancy are associated with impaired psychomotor development in infancy. Clin Endocrinol (Oxf). 1999; 50: 149-155.

PubMed: https://pubmed.ncbi.nlm.nih.gov/10396355/

77. Pharoah POD, Buttfield IH, Hetzel BS. Neurological damage to the fetus resulting from severe iodine deficiency during pregnancy. Lancet. 1971; 297:308-310.

PubMed: https://pubmed.ncbi.nlm.nih.gov/4100150/

78. Cao XY, Jiang XM, Dou ZH, Rakeman MA, Zhang ML, O'Donnell KJ, et al. Timing of vulnerability of the brain to iodine deficiency in endemic cretinism. N Engl J Med. 1974; 331:1739-1744.

PubMed: https://pubmed.ncbi.nlm.nih.gov/7984194/

79. Torlinska B, Bath SC, Janjua A, Boelaert K, Chan SY. lodine status during pregnancy in a region of mild-to-moderate iodine deficiency is not associated with adverse obstetric outcomes; results from the Avon Longitudinal Study of Parents And Children (ALSPAC). Nutrients. 2018; 10: 291.

PubMed: https://pubmed.ncbi.nlm.nih.gov/29494520/

80. Hynes KL, Otahal P, Hay I, Burgess JR. Mild iodine deficiency during pregnancy is associated with reduced educational outcomes in the offspring: 9-year follow-up of the Gestational lodine Cohort. J Clin Endocrinol Metab. 2013; 98: 1954-1962.

PubMed: https://pubmed.ncbi.nlm.nih.gov/23633204/

81. Abel MH, Caspersen IH, Meltzer HM, Haugen M, Brandlistuen RE, et al. Suboptimal maternal iodine intake is associated with impaired child neurodevelopment at 3 years of age in the Norwegian Mother and Child Cohort Study. J Nutr. 2017; 147: 1314-1324. PubMed: https://pubmed.ncbi.nlm.nih.gov/28515161/

82. Markhus MW, Dahl L, Moe V, Abel MH, Brantsæter AL, et al. Maternal lodine Status is Associated with Offspring Language Skills in Infancy and Toddlerhood. Nutrients. 2018; 10: 1270. PubMed: https://pubmed.ncbi.nlm.nih.gov/30205599/

83. Iodine Global Network. Global scorecard of iodine nutrition in 2017 in the general population based on school-age children (SAC) with additional data for pregnant women (PW) [Internet]. Zurich, Switzerland: lodine Global Network. 2017.

84. Rebagliato M, Murcia M, Alvarez-Pedrerol M, Espada M, FernándezSomoano A, et al. lodine supplementation during pregnancy and infant neuropsychological development. INMA Mother and Child Cohort Study. Am J Epidemiol. 2013; 177: 944-953.

PubMed: https://pubmed.ncbi.nlm.nih.gov/23548753/

85. Berbel P, Mestre JL, Santamaría A, Palazón I, Franco A, et al. Delayed neurobehavioral development in children born to pregnant women with mild hypothyroxinemia during the first month of gestation: the importance of early iodine supplementation. Thyroid. 2009; 19:511-519. PubMed: https://pubmed.ncbi.nlm.nih.gov/19348584/

86. Velasco I, Carreira M, Santiago P, Muela JA, García-Fuentes E, et al. Effect of iodine prophylaxis during pregnancy on neurocognitive development of children during the first two years of life. J Clin Endocrinol Metab. 2009; 94: 3234-3241.

PubMed: https://pubmed.ncbi.nlm.nih.gov/19567536/ 
87. Zhou SJ, Anderson AJ, Gibson RA, Makrides M. (2013) Effect of iodine supplementation in pregnancy on child development and other clinical outcomes: a systematic review of randomized controlled trials. Am J Clin Nutr. 2013; 98: 1241-1254.

PubMed: https://pubmed.ncbi.nlm.nih.gov/24025628/

88. Chaouki ML, Benmiloud M. Prevention of iodine deficiency disorders by oral administration of lipiodol during pregnancy. Eur $\mathrm{J}$ Endocrinol. 1994; 130: 547-551.

PubMed: https://pubmed.ncbi.nlm.nih.gov/8205252/

89. Qian M, Wang D, Watkins WE, Gebski V, Yan YQ, et al. The effects of iodine on intelligence in children: a meta-analysis of studies conducted in China Asia Pac J Clin Nutr. 2005; 14: 32-42.

PubMed: https://pubmed.ncbi.nlm.nih.gov/15734706/

90. Censi S, Watutantrige-Fernando S, Groccia G, Manso J, Plebani M, et al. The Effects of lodine Supplementation in Pregnancy on lodine Status, Thyroglobulin Levels and Thyroid Function Parameters: Results from a Randomized Controlled Clinical Trial in a Mild-toModerate lodine Deficiency Area. Nutrients. 2019; 11: 2639. PubMed: https://pubmed.ncbi.nlm.nih.gov/31689890/

91. Taylor PN, Okosieme OE, Dayan CM, Lazarus JH. Therapy of endocrine disease: Impact of iodine supplementation in mild-tomoderate iodine deficiency: systematic review and meta-analysis. Eur J Endocrinol. 2013; 170: R1-R15.

PubMed: https://pubmed.ncbi.nlm.nih.gov/24088547/

92. Rebagliato M, Murcia M, Espada M, Alvarez-Pedrerol M, Bolumar F, et al. lodine intake and maternal thyroid function during pregnancy. Epidemiology. 2010; 21: 62-69.

PubMed: https://pubmed.ncbi.nlm.nih.gov/19940773/

93. Mohammed H, Marquis GS, Aboud F, Bougma K, Samuel A. Prepregnancy lodized Salt Improved Children's Cognitive Development in Randomized Trial in Ethiopia. Matern Child Nutr Jul. 2020; 16: e12943. PubMed: https://pubmed.ncbi.nlm.nih.gov/31912649/

94. Fishpool MDH, Rayman MP, Mendis J, Bath SC. Systematic Review and Meta-Analysis of the Effects of lodine Supplementation on Thyroid Function and Child Neurodevelopment in Mildly-To-Moderately lodineDeficient Pregnant Women. Am J Clin Nutr. 2020; 112: 389-412. PubMed: https://pubmed.ncbi.nlm.nih.gov/32320029/

95. Markou K, Georgopoulos N, Kyriazopoulou V, Vagenakis AG. lodineInduced hypothyroidism. Thyroid. 2001; 11: 501-510. PubMed: https://pubmed.ncbi.nlm.nih.gov/11396709/

96. Shi X, Han C, Li C, Mao J, Wang W, et al. Optimal and safe upper limits of iodine intake for early pregnancy in iodine-sufficient regions: a crosssectional study of 7190 pregnant women in China. J Clin Endocrinol Metab. 2015; 100: 1630-1633.

PubMed: https://pubmed.ncbi.nlm.nih.gov/25629356/

97. De Groot L, Abalovich M, Alexander EK. Management of thyroid dysfunction during pregnancy and postpartum: an endocrine society clinical practice guideline. J Clin Endocrinol Metab. 2012; 97: 2543-2565. PubMed: https://pubmed.ncbi.nIm.nih.gov/22869843/

98. Institute of Medicine Food and Nutrition Board. Dietary Reference Intakes. Washington (DC): National Academies Press; 2006.
99. WHO. lodine supplementation in pregnant and lactating women. Geneva: World Health Organization; 2016.

100. Andersson M, de Benoist B, DelangeF, Zupan J. WHO Secretariat. Prevention and control of iodine deficiency in pregnant and lactating women and in children less than 2-years-old: conclusions and recommendations of the Technical Consultation. Public Health Nutr. 2007; 10: 1606-1611.

PubMed: https://pubmed.ncbi.nlm.nih.gov/18053287/

101. Romano R, Jannini EA, Pepe M, Grimaldi A, Olivieri M, et al. The effects of iodoprophylaxis on thyroid size during pregnancy. Am J Obstet Gynecol. 1991; 164: 482-485.

PubMed: https://pubmed.ncbi.nlm.nih.gov/1992688/

102. Pedersen KM , Laurberg P, Iversen E, Knudsen PR, Gregersen HE, et al. Amelioration of some pregnancy-associated variations in thyroid function by iodine supplementation. J Clin Endocrinol Metab. 1993; 77:1078-1083.

PubMed: https://pubmed.ncbi.nlm.nih.gov/8408456/

103. Fierro-Benitez R, Cazar R, Stanbury JB, Rodriguez P, Garces F, et al. Effects on schoolchildren of prophylaxis of mother with iodized oil in an area of iodine deficiency. J Endocrinol Inves. 1988; 11: 327-335. PubMed: https://pubmed.ncbi.nlm.nih.gov/2846675/

104. Glinoer D, De Nayer P, Delange F, Lemone M, Toppet V, et al. A randomized trial for the treatment of mild iodine deficiency during pregnancy: maternal and neonatal effects. J Clin Endocrinol Metab. 1995; 80: 258-262.

PubMed: https://pubmed.ncbi.nlm.nih.gov/7829623/

105. Becker DV, Braverman LE, Delange F, Hollowell JG, Lamm SH, et al. lodine supplementation for pregnancy and lactation-United States and Canada: recommendations of the American Thyroid Association. Thyroid. 2006; 16: 949-995.

PubMed: https://pubmed.ncbi.nlm.nih.gov/17042677/

106. WHO Secretariat, Andersson M, de Benoist B, Delange F, Zupan J. Prevention and control of iodine deficiency in pregnant and lactating women and in children less than 2-years-old: conclusions and recommendations of the Technical Consultation. Public Health Nutr. 2007; 10:1606-1611.

PubMed: https://pubmed.ncbi.nlm.nih.gov/18053287/

107. WHO/UNICEF. Reaching optimal iodine nutrition in pregnant and lactating women and young children. Joint Statement by the WHO and the UNICEF. World Health Organization, Geneva. 2007.

108. International Council for Control of lodine Deficiency Disorders. Iodine requirements in pregnancy and infancy. IDD Newsletter. 2007; 23: 1-2.

109. Alexander EK, Pearce EN, Brent GA, Brown RS, Chen H, et al. 2017 Guidelines of the American Thyroid Association for the Diagnosis and Management of Thyroid Disease During Pregnancy and the Postpartum. Thyroid. 2017; 27: 315-389.

PubMed: https://pubmed.ncbi.nlm.nih.gov/28056690/

110. De Groot L, Abalovich M, Alexander EK, Amino N, Barbour L, et al. Management of thyroid dysfunction during pregnancy and postpartum: an Endocrine Society clinical practice guideline. J Clin Endocrinol Metab. 2012; 97: 2543-2565.

PubMed: https://pubmed.ncbi.nlm.nih.gov/22869843/ 